\title{
Cordonnier Grade 2 Parasitic Complication, Toxoplasmosis Infection without Organ Involvement
}

National Cancer Institute

\section{Source}

National Cancer Institute. Cordonnier Grade 2 Parasitic Complication, Toxoplasmosis

Infection without Organ Involvement. NCI Thesaurus. Code C138311.

Any Toxoplasmosis infection without organ involvement. 